\title{
The Burden of the Burden: Current Advances in Weight Stigma Research
}

\author{
Anja Hilbert \\ Department of Psychology, University of Fribourg, Switzerland
}

Beyond the burden of obesity-related physical co-morbidity, obese individuals frequently suffer from significant social and psychological impairment. Weight stigma and, more specifically, the experience of being subjected to negative weightrelated stereotypes and discrimination plays a major role in this psychosocial sequelae: Accumulating evidence shows that perceived weight-related discrimination is associated with a range of psychopathology in obese adults, including depression, anxiety, low self-esteem, disordered eating, negative body image and decreased quality of life $[1,2]$. In youth, experiencing weight-related discrimination has been found to increase the likelihood of later developing psychopathology [3]. Further evidence indicates that weight-related discrimination coincides with poor health behavior, such as overeating, binge eating or decreased physical activity. This in turn will lead to greater weight gain, which again may increase the risk of exposure to weight-related discrimination, and so forth, forming a vicious cycle. Perceived discrimination could even mediate the association between obesity and physical disease parameters [4]. These threats to and impairments in health are likely magnified by the social backdrops of weight stigma: Obese individuals have to face disadvantages in multiple domains of living, such as work or school, interpersonal relationships and health care, which can lead to decreased professional success, decreased likelihood of having fulfilling relationships and decreased health care utilization and provision [5-7].

Given this significant sequelae, the question remains as to how to reduce weight stigma and prevent or manage its harmful effects. Stigma reduction is complicated by the fact that weight stigma is so pervasive in the Western, industrialized countries that it can be considered normative $[8,9]$. Many people, including those who are professionally concerned with weight management, hold stigmatizing attitudes towards obese persons. Even highly credible news media convey weight-based devaluations $[10,11]$. Research that ex- amines the foundation of weight stigma shows that stigmatizing attitudes are socioculturally enrooted in conservative ideologies [12] such as the Protestant work ethic or the belief that one gets what one deserves, associated with beliefs of personal responsibility [13]. Interventions to overcome weight stigma and its detrimental effects have been developed that are based upon the knowledge of the foundation and process of weight-related stigmatization and discrimination. Several of these approaches have emerged as promising [14]. However, these interventions have only produced short-term changes, and it thus remains largely unclear how interventions would need to be designed in order to promote substantial and long-lasting change in people's views and to ultimately decrease weight-related discrimination. An additional and related question is how overweight and obese individuals could be supported in order to effectively cope with weight stigma and attenuate its deleterious effects, for example, within health promotion and the prevention and treatment of obesity [15].

The current special issue about weight stigma compiles original research and review articles on weight stigma research. Two empirical studies address the experience of weight-related discrimination in obese adults. Using focus group methodology, Hayden et al. [16] explore the thoughts and feelings about being overweight and weight loss among obese individuals who had undergone gastric banding. These accounts provide insight into the influence of weight stigma on the perceived gains and losses from the surgical treatment of obesity. Schmalz [17] investigates the impact of weight stigma on poor health behavior, especially on decreased physical activity, and explores the mediation of this association through body esteem or body mass index in obese adults. Knowledge of these psychosocial processes is important to design interventions tackling barriers to physical activity, for example, in health promotion or weight management.

\section{KARGER}

Fax +497614520714

Information@Karger.de

www.karger.com (c) 2010 S. Karger GmbH, Freiburg

Accessible online at:

www.karger.com/ofa 
Two qualitative reviews focus on weight stigma in specific settings. Giel et al. [18] provide an overview of weight stigma research in work settings in order to determine whether obesity represents a barrier to employment and professional success and is thus associated with real impediments to leading a productive life. Ata and Thompson [19] summarize weight stigma research on a wide range of child and adult media, including television shows, movies, books, newspapers and the internet. The authors focus on bias in media representations of overweight and obesity, on the effects of exposure to such media and on the largely untapped potential of the media to correct stigmatizing attitudes.

Given that weight bias is present from an early age makes children vulnerable to psychopathology; it is thus necessary to have both explicit and implicit measures of stigmatizing attitudes available for this age group. While social norms may prevent people from openly admitting their thoughts, implicit measures allow researchers access to non-conscious stigmatizing attitudes that are less likely influenced by response biases. Solbes and Enesco [20] use a developmental perspective to present a child-specific adaptation of the Implicit Association Test contrasted with the results of explicit measures. The qualitative review of research methodology by Ruggs et al. [21] provides a practical overview of methods for weight stigma assessment in children and adults. Until now, few instruments have been validated, and scale development has not frequently utilized state-of-the-art methodology [16]. The authors also place emphasis on the design of field studies that have ecological validity, but have been used only rarely to study of real-life processes of weight-related discrimination.

To conclude, Daníelsdóttir et al. [22] present a comprehensive overview of evidence on stigma reduction. They discuss targets, interventions, methods and design issues to be considered in future intervention research in order to develop effective approaches to stigma reduction.

All articles in this special issue were subject to peer review by two external reviewers and the associate editor, resulting in one or multiple revisions to ensure the quality of the papers. We hope that the articles in this special issue will stimulate further research. Although research evidence on weight stigma is growing, the evidence still remains insufficient. Further research is needed to more fully understand the development, nature and consequences of weight stigma in diverse sociodemographic populations. Research is also needed to develop evidence-based measures to reduce weight stigma and its harmful effects on the health and well-being of overweight and obese individuals.

\section{References}

1 Puhl R, Brownell KD: Bias, discrimination, and obesity. Obes Res 2001;9:788-805.

2 Puhl RM, Heuer CA: The stigma of obesity: a review and update. Obesity 2009;17:941-964.

3 Puhl RM, Latner JD: Stigma, obesity, and the health of the nation's children. Psychol Bull 2007;133: 557-580.

$\checkmark 4$ Muennig P: The body politic: the association between stigma and obesity-associated disease. BMC Public Health 2008;8:128-141.

5 Johansson E, Bockerman P, Kiiskinen U, Heliovaara M: Obesity and labour market success in Finland: the difference between having a high BMI and being fat. Econ Hum Biol 2009;7:36-45.

6 Carr D, Jaffe KJ, Friedman MA: Perceived interpersonal mistreatment among obese Americans: do race, class, and gender matter? Obesity 2008; 16(suppl 2):S60-68.

7 Fabricatore AN, Wadden TA, Foster GD: Bias in health care settings; in Brownell KD, Puhl RM, Schwartz MB, Rudd L (eds): Weight Bias Nature, Consequences, and Remedies. New York, Guilford Press, 2005, pp 29-41.

8 Hilbert A, Rief W, Braehler E: Stigmatizing attitudes toward obesity in a representative populationbased sample. Obesity 2008;16:1529-1534.

9 Hansson LM, Karnehed N, Tynelius P, Rasmussen F: Prejudice against obesity among 10-year-olds: a nationwide population-based study. Acta Paediatr 2009;98:1176-1182.
10 Greenberg BS, Worrell TR: The portrayal of weight in the media and its social impact; in Brownell KD, Puhl RM, Schwartz MB, Rudd L (eds): Weight Bias Nature, Consequences, and Remedies. New York, Guilford Press, 2005, pp 42-53.

11 Hilbert A, Ried J: Obesity in print: an analysis of German newspapers. Obes Facts 2009;2:46-51.

12 Puhl RM, Brownell KD: Psychosocial origins of obesity stigma: toward changing a powerful and pervasive bias. Obes Rev 2003;4:213-227.

13 Crandall CS, Reser AH: Attributions and weightbiased prejudice; in Brownell KD, Puhl RM, Schwartz MB, Rudd L (eds): Weight Bias Nature, Consequences, and Remedies. New York, Guilford Press, 2005, pp 83-96.

14 Puhl RM, Schwartz MB, Brownell KD: Impact of perceived consensus on stereotypes about obese people: a new approach for reducing bias. Health Psychol 2005;24:517-525.

15 MacLean L, Edwards N, Garrard M, Sims-Jones N, Clinton K, Ashley L: Obesity, stigma and public health planning. Health Promot Int 2009;24:88-93.

16 Hayden MJ, Dixon ME, Dixon JB, Playfair J, O'Brien PE: Perceived discrimination and stigmatisation against severely obese women: age and weight loss make a difference. Obes Facts 2010; 3(1):7-14.
7 Schmalz DL: 'I feel fat': weight related stigmas, body esteem, and BMI as predictors of perceived competence in physical activities. Obes Facts 2010; 3(1):15-21.

18 Giel KE, Thiel A, Teufel M, Mayer J, Zipfel S: Weight bias in work settings. Obes Facts 2010; 3(1):33-40.

19 Ata R, Thompson JK: Weight bias in the media: a review of recent research. Obes Facts 2010;3(1): 41-46.

20 Solbes I, Enesco I: Explicit and implicit antifat attitudes in children and its relationships with their body image. Obes Facts 2010;3(1):23-32

21 Ruggs EN, King EB, Hebl M, Fitzsimmons M: Assessment of weight stigma. Obes Facts 2010;3(1): 60-69.

22 Morrison TG, Roddy S, Ryan TA: Methods for measuring attitudes about obese people; in Allison DB, Baskin ML (eds): Handbook of Assessment Methods for Eating Behaviors and Weight-Related Problems. Measures, Theory, and Research, 2nd ed. Thousand Oaks, Sage Publications, 2009, pp 79-114.

23 Daníelsdóttir S, O'Brien KS, Ciao A: Anti-fat prejudice reduction: a review of published studies. Obes Facts 2010;3(1):47-58. 